\title{
4. Digital Gifts and Rituals
}

\begin{abstract}
In Chapter 4 we revisit historical discussions around mobile media as gift and the important anthropological meanings of the gift as a practice into power relations and rituals, to think about how we might expand upon this practice in terms of location. Here location, co-location and co-presence are revisited.
\end{abstract}

Keywords: gift-giving; co-presence; location

In Tokyo, Shizuka, a 21-year-old undergraduate student, lived with her mother (50-year-old), father (54-year-old) and younger sister (19-year-old). She used LINE regularly with her family. Her father worked in a major consumer electronics company and knew a great deal about the latest equipment such as computers and smartphones and was also an early adopter of LINE (See Chapter 2). Shizuka's mother had also started to use smartphones and LINE a few years earlier. Initially, she was not very comfortable using social mobile media, but over the past year her husband and her daughter had used stamps to integrate her into family life.

For Shizuka's family, stamps on LINE became one of the daily rituals of family life. Building on the use of emojis and kawaii culture in Japan, stamps provided playful ways to share feelings and emotions, providing a sense of co-presence throughout the day. Often the family would share stamps during specific moments of the day such as lunchtime and at the end of the day.

LINE had even invented stamps to share just between parents-conveying tacit and phatic forms of communication. Emojis and their next iteration, stamps, amplify the significant symbolic role of mobile media in maintaining co-present feelings and rituals when physically distant. They play into broader gift giving cultures that are both culturally specific and also transnational.

Hjorth, L., K. Ohashi, J. Sinanan, H. Horst, S. Pink, F. Kato, B. Zhou, Digital Media Practices in Households: Kinship through Data. Amsterdam: Amsterdam University Press, 2020 DOI 10.5117/9789462989504_CHO4 


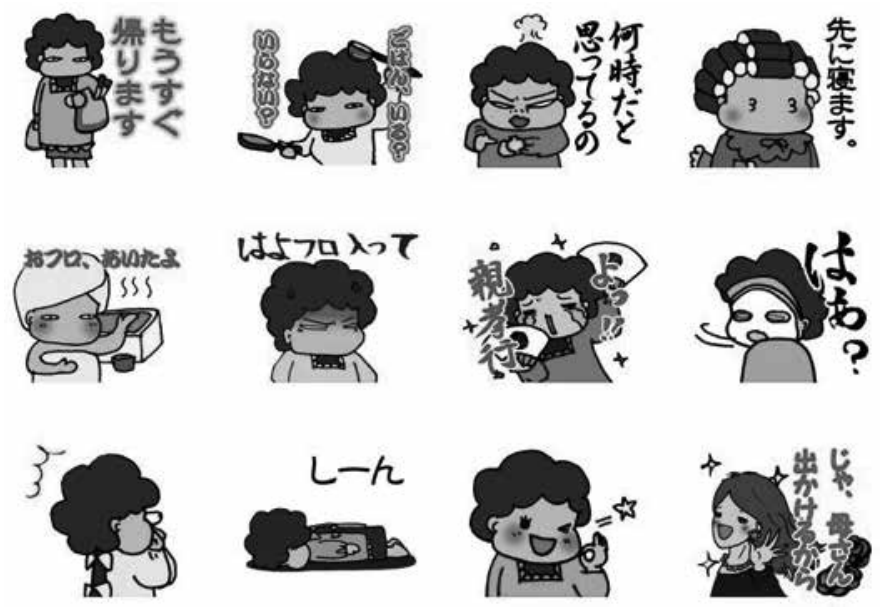

Figure 4.1: LINE stamps for mums

Building upon the discussion of friendly surveillance in the previous chapter, this chapter highlights the more playful forms of kinship-including the exchange of gifts and daily rituals - that are emerging through locative media. Gift cultures have a long and culturally specific history. The symbolic role of gift giving - as a practice of reciprocity, obligation and negotiating power relations - has long been attached to mobile media cultures (Taylor and Harper 2002). Gift exchange and attendant rituals help to make visible issues such as obligation and care and the multiple ways that locative and social media has come to shape digital kinship. Specifically, this chapter highlights how everyday play with digital gifts and rituals in contemporary family life enables the maintenance of family through creating forms of co-presence and related feelings of intimacy.

\section{The Cultural Dimensions of Gifts and Rituals}

There is nothing inherent in objects that designate them as gifts; objects can almost always follow varying trajectories. Precisely, gifts are not objects, but transactions and social relations (Frow 1997, 124).

Within disciplines such as anthropology, gifts and rituals represent some of the glue that keeps society cohesive. Whether it be through non-capitalist forms of exchange such as the Melanesian kula ring-a complex system that govern the rules of exchange and reciprocity (Weiner 1992; Malinowski 2014; Mauss 2016) — or the Native American potlach where gift giving is tied 
to forms of wealth display (Mauss 2016). There are also the more mundane practices around the sharing of food among families in the US over thanksgiving (see Kohn 2013) or gift giving at holidays such as Christmas (Miller 1995). In consumer cultures such as the US, gifts play an important role in the sustainability of the broader social structure.

Whether or not the rules of society include more calculated forms of reciprocity or generalized reciprocity for the broader social group remains a key issue. For example, in Malinowski's Argonauts of the Western Pacific (2014), he argues that reciprocity emerges as a key theme, but not in terms of mutual benefit. Rather, reciprocity is seen as an uneven power relationship that favors the giver of the gift, forcing the recipient into an ongoing "chain of reciprocal gifts and counter-gifts" (Ibid., 40) in order not to "lose face" within the tribe (see Weiner 1992 for a discussion of the gendered dimensions of gift giving).

Comparing different forms of gift exchange around the world, Mauss departs from Malinowski by reviewing the notion of reciprocity as a process primarily derived from (and also perpetuated by) underlying societal rules (Bergquist and Ljungberg 2001, 308-309; Taylor and Harper 2005, 441). For Mauss, it is impossible to extricate gift exchange from the social because gift exchange is itself the basis for all forms of exchange within many nonWestern societies, "a total social fact" that underpins all forms of social exchange be they religious, social, moral, juridical, familial or economic (Bergquist and Ljundberg 2001, 309; Mauss 2002, 3-4; Jarrett 2015, 206-207, 211).

Importantly, Mauss also refines Malinowki's ideas on reciprocity by aligning reciprocity with obligation. In doing so, Mauss identifies three types of obligation relative to gift exchanges - the obligation to give (one must give), the obligation to receive (one must accept the offering) and the obligation to return/reciprocate (when given a gift, an appropriate gift must be returned) (Frow 1997, 108; Mauss 2016, 10, 50). This notion of social obligation is crucial—often shaping contemporary motivations and practices around the use of mobile media for care at a distance. It is important to recognize that care isn't always without obligation. For example, parents and children share particular rituals around digital kinship that are underscored by obligation (i.e. obliged to respond to a social media post).

John Frow in Time and Commodity Culture (1997) — and "Information as Gift and Commodity" (1996) — addresses an alternative aporia: the disparity when gift and commodity economies coincide. For Frow $(1997,102,124-126$, 130), there are no societies in which gift and commodity exchanges are not co-present-nor can the two modes of exchange be seen in purely binary 
term. While gifting and commodities can be understood in "ideal" terms as distinct systems, whenever they meet a "recurrent lack of commensurability between a gift relation on one side and a commodity relation on the other" emerges (Frow 1996, 97-98). Ultimately, Frow concludes that while reading information commodification through the lens of gift/commodity economies is useful, "the concept of gift is irrelevant to the structural understanding of modern societies, with the exception of the micro-level of everyday life" (Ibid., 107-108).

Turning to the mobile phone, Alex S. Taylor and Richard Harper's (2002) "Age-old Practices in the New World-and "Gift of the Gab" with Sara Berg-picks up directly from Frow by analyzing social practices of gift exchange through "everyday" observation. Their chapter-a four-month ethnographic study of British teenagers' use of their mobile phones-shows that the teenagers' mobile practices closely resemble notions of gift exchange (Berg, Taylor and Harper 2005, 440). Specifically, Mauss' system of reciprocity was particularly prevalent wherever SMS transactions between teens was observed (Taylor and Harper 2005, 441).

From feeling of obliged to respond to SMS transactions through to carefully managed intervals between receipt of SMS and reciprocal response, the "social obligation to exchange" was displayed by all participants variously throughout the study (Ibid., 440-444). A key feature of the study was the mixture of reports based on instances where participants were engaging in mobile communications in isolation and also using their phones in the company of others. In either case, patterns of behavior akin to Mauss' system of reciprocity generally exhibited, especially in relation to social status based on open displays of friendship/alliance or rivalry-passing phones to one another, establishing "sideplays" by only sharing with one other group member, etc. (Ibid.).

What becomes apparent in our discussion of the gift—as part of kinships rituals - is the way in which media practices can function to both extend existing rituals of reciprocity and exchange as well as creating new ones. By viewing the context of Australia, which shares many gift giving rituals with other Western contexts such as England and the US, alongside two locations with rich histories of gift giving - Japan and China-we can see the multiple ways in which the gift as kinship plays out. For example, Chinese notions of guanxi (social capital) play into gift cultures and power relationships (Hjorth and Arnold 2013).

Japanese culture traditionally values seasonal greetings and gifts in order to maintain relationships. In mid-summer and the end of the year, family, friends and co-workers send gifts to people such as colleagues, 
bosses, relatives, and teachers in order to express gratitude. It contributes not only to shaping and reshaping relationships, but also to acknowledge and feel the changes of season. By sending such gifts periodically, they nourish the sense of closeness or of growing together. Also, every January, they send postcards to friends, relatives and colleagues to greet the New Year (like the western tradition of sending/receiving Christmas cards in December).

While the Japanese custom of sending New Year's greeting still remains, in contemporary culture paper postcards are replaced by electronic versions. In particular, the active use of emoji or stamps over social media may resonate well with Japanese culture of periodical gift giving. As we highlight in this and the following chapters, sending photos and stamps can be understood as a form of gift, through which we develop and nurture our relationships and, through these practices, a remediation of postcards in the form of electronic paralinguistic sharing (Hjorth 2005).

In Shanghai, gift giving is one of the most important forms of social exchange. Gifts build up the inter-dependent relationship, i.e., Guanxi, between different people (see Yang 1994). Chinese society is rather mobile and individual-centered, and gifts play a vital role in maintaining, building and transformation interpersonal relationship in China (Jacobs 1979; Walder 1986; Yang 1989). According to Yoon et al. (2011), there are three primary goals to engage in gift giving practices in China: to manage one's social status, to maintain or improve relationships, as well as to demonstrate conformity to agreed social norms. Gift giving culture can be dated back to ancient China. As a Chinese saying goes, courtesy requires a return of visits received. A state of ceremonies as it is, China has numerous historical stories of gift giving and emphasizes the importance of two-way exchange of gifts both in the aspect of folk tradition and diplomacy.

During the Spring and Autumn Period (770 B.C-221 B.C), when the territory was separated into several states, there were gift-exchanging cases between regimes. It was also the Chinese tradition to send gifts among civilians. The most common and in-style way of gift giving today is the Red Pocket. Sending red pocket is a typical Chinese tradition, which means the seniors give lucky money to the young, in order to wish the young luck in the coming year. During the 2015 Spring Festival, WeChat developed its Red Pocket function into an app. According to Tencent (2016), the total sending and receiving amount of WeChat Red Pocket on the eve of Chinese lunar year reached 101 million.

In the following section we focus upon forms of digital gifts and rituals that have emerged in the intergenerational families in this study. Specifically, 


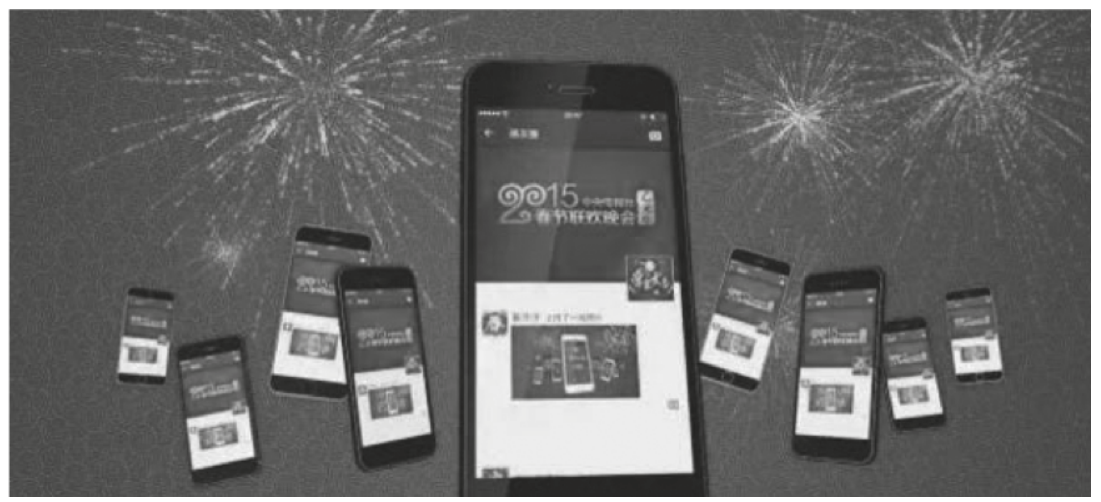

Figure 4.2: WeChat Happy New Year gifting

we will focus upon two, interrelated forms of gift giving which has become part of the playful ways in which kinship is produced and reproduced in Shanghai, Tokyo and Melbourne. The first is the use of digital gifts for mundane forms of domestic care where the intimate mundane emerges in and through social and locative media use. The second is the use of digital gifts to create and maintain intimate rituals within families and in the final section we see how practices around disclosure enable family members to enact one of the classic practices of gifting, keeping while giving (Raheja 1988; Weiner 1992).

\section{Digital Gifts and Domestic Care}

In Melbourne the gift plays a role in maintaining social relationships (Ling and Yttri 2001; Hjorth 2005). Texting and/or sharing location on the way home from work (e.g. "I'm on my way home, should I pick up milk"), is a mundane practice that reinforces ties of connection and the reproduction of the household, what Ling and Yttri have referred to as "micro-coordination" of family life. Here domestic care operated as a gift culture in the maintenance of daily rituals.

For 6o-year-olds Dina and Mike Harrison, texting at the beginning and end of Mike's day was a comfort. Dina retired in February 2015 and was adjusting to life at home in Melbourne. She also suffered from arthritis and didn't leave the house for prolonged hours. Mike worked in a state correction center, where his job could be dangerous at times. As he couldn't have his mobile phone on him, he would call Dina from a landline when he arrived and before he left for home. Mike explained that the end of the day phone 
call was to let Dina know his day at work had gone well with no incidents and also to find out what kind of day she had had, how she was feeling and if anything had been particularly difficult for her, in order to prepare himself for the evening. As Mike explained:

I can find out what kind of mood Dina is in, with her arthritis if she's having an ok day or a terrible day I'll know, sometimes I'll wish I could go home now but it does help me prepare for what I'm going home to. It is a mental thing, but you do it automatically. You can tell by the sound of her voice. But I also like to ring and say hi.

Mike also let Dina know if he was going to pass the local shops when he was on the way home, in case she would like anything, especially if she had not left the house during the day. Texting on the way home from work emerged as a consistent practice between couples at different life stages in Melbourne. Ben (31-year-old) and Jasmine, for example, sent text messages over Facebook Messenger almost every day in order to coordinate their evening. Ben played soccer a couple of days a week and Jasmine had work or social plans most evenings, so they often let each other know of their upcoming movements for the evening to coordinate having meals together, or so Ben could make plans if Jasmine was already planning to be out for the evening.

Another couple, Lily and Christopher Turner (30-year-old), had two sons aged three and five. Lily finished work half an hour before Christopher and arrived home to start making dinner. A usual evening involved Lily cooking after work, Christopher arriving home, where they would all eat together before giving the boys a shower, then half an hour of play or reading time before putting the boys to bed. Lily and Christopher also texted each other every day when they were leaving work. As Christopher described:

In terms of being considerate and knowing what to expect, it probably matters more with the boys. Like being home by 6 wasn't as big a consideration when you're not going to have dinner 'til 7 and it's not boys finishing dinner and getting ready for showers and things. 5 or 10 makes a difference with kids, it's not the be all and end all but it's helpful.

Lily added, "Or if they're giving me a really hard time. Sometimes I just need him home. Like if I know I just have to survive another 10 minutes and he'll be home." Like the use of phone calls to micro-coordinate daily life, gift giving in Japan can also be seen through the sharing of familial information regarding their day-to-day routines. 


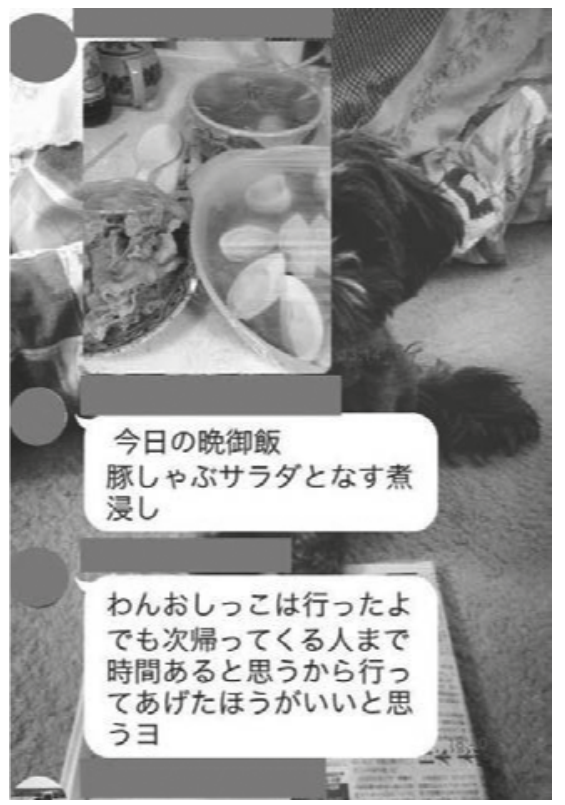

Figure 4.3: Saori and symbolic gift giving through maintenance on LINE

Saori, a 21-year-old undergraduate student, lived with her mother (49-yearold), father (51-year-old) and younger sister (21-year-old). Saori and her family used LINE for making contact with each other. In their LINE family group, the main topics were "food and the dog." Her mother would send a message about and a photo of "today's dinner" almost every weekday, usually to say something like, "please warm this before eating." They would also talk about who would take a dog for a walk.

Saori's mother's message "please warm this before eating" suggested that whereas family members were connected through LINE group to coordinate things, they would not be not eating together that particular day and the first person to get home might eat alone. In Shanghai, sharing location is also a normative practice between family members. For near-by family members, sharing locative information was a helpful practice for the micro-coordination of domestic life.

50-year-old father Jun and 45-year-old mother Qin exchange often through the family WeChat group. As a typical Shanghai father, Qin was in charge of preparing food for the family every day. In the red rectangle, Qin was saying that he was at the market and asking his family members for suggestions for the dinner. "It is really hard for me to design the daily menu," he said, "by asking my family's preference for dinner, it saved time." 
In essence, families in Melbourne, Shanghai and Tokyo used mobile, social and locative media to manage the vagaries of everyday life and the reproduction of the family. Whether it involved phone calls home to assess the mood of a spouse coping with an illness, a new life stage or the management of children or posts to share the preparation of dinner, social, mobile and locative media become part of the mundane forms of care in families. These small "check-ins" to micro-coordinate the activities of the household and the family thus represent forms of everyday (digital) gift giving in families. While mundane, family members noted their absence or delay, and the exchange of information was part of the reciprocity involved in reproducing the household.

\section{Digital Gifts as Intimate Co-presence}

Alongside the more instrumental use of the phone to micro-coordinate domestic life across the three sites in this study, we also saw the emergence of digital gifts in the full-time intimate communities (Ito, Matsuda and Okabe 2005) that constitute co-presence. Co-presence is an important part of maintaining social relations in everyday rituals. In our research, we saw the sharing of events happening in other places on a variety of platforms through tagging on sites such as Facebook, SMS direct messaging or WhatsApp. These often produced a sense of mundane intimacy, both creating and reinforcing a sense of familiarity.

In Shanghai, the creation of co-presence through social and locative media has become a key way through which families manage separation and distance. As children grow older, it is common for Chinese children to gradually leave their beloved hometown and start their new life alone in a faraway city without parents' company. Due to the one-child policy carried out in the 1980 s in China, the majority of Chinese university students today are the only children in their family. Parenting thus involved extensive care during their childhood and, as they move forward in life without their parents physically by their side, it also involves worry and concern. Sharing information and events within digital family groups thus effectively creates a virtual domestic space where family members feel co-present.

Thanks to the rich media content available on WeChat, Chinese users have various ways of sharing interesting life events with distant families so as to let remote family members get involved in the event at the same time by creating virtual co-presence. 


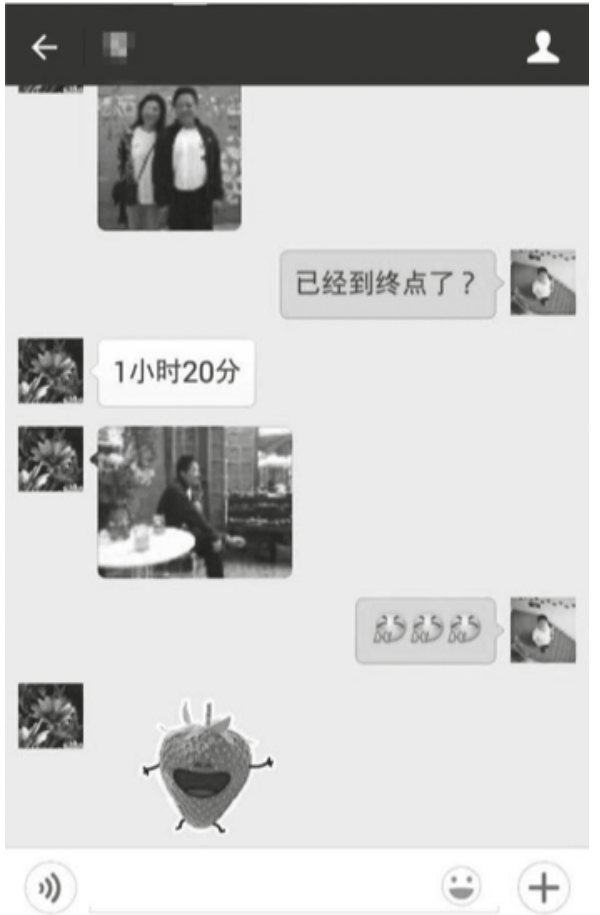

Figure 4.4: Kevin's family WeChat group

Figure 4.4 is a screenshot of Kevin's family WeChat group. Kevin, the participant on the right, was a 22-year-old boy from a Shanghai suburb who was studying in downtown Shanghai. Although Kevin was lucky enough not to leave his hometown to further his study, he only went back home once a month due to school commitments. According to his 50-year-old parents, they did not have much time to have face-to-face communication with Kevin. Therefore, the family WeChat group played a vital role in daily communication.

One weekend when Kevin was at school as usual, his parents took part in a hiking competition and took 80 minutes to finish the full distance. In Figure 4.4, Kevin's mother (on the left) shared a photo of both parents taken at the destination of the hiking competition and Kevin replied with cheerful emotional icons to congratulate. By sharing photos and text information, Kevin's family were able to be together during the hiking competition, which created a sense of daily intimacy, as if they were still by each other's side.

In Melbourne many of the migrant families we interviewed discussed sharing pictures of food, flowers or other things that they believed other family members would find of interest while separated. For example, Nancy 
used her iPhone to take, store and send photos and said, "I love photos. Sometimes, say, I take photos of my daughter, she is learning to cook so I take photos just to have a record." She sent several of her photos to her relatives overseas. As Nancy described:

My extended family, my cousins and aunties in Singapore. Just share because they don't have the opportunity to cook much over there. They do cook different things, they would like to bake more but they don't have that kind of equipment like here and it's hot over there as well so sometimes baking is not a conducive thing. And sometimes if we go for occasions we'll share, so some things that the family do.

While Nancy might share some of the things she did with her family on Facebook, where her photos might be seen by others, she shared photos of things she was more interested in with only certain people over WhatsApp such as photos of her garden and collages that she liked to do. She took photos and sent them overseas, commenting "because in Singapore they don't have much land to grow things so I love gardening, so I take all kinds of (photos) like plants and things like that and I show them fruits that's fruiting."

Through photos Nancy shared the kinds of things she would have shared with her extended family had she been living in Singapore. Occasions and meals were an important part of shared family time, where photos helped to fill some of the distance between relatives overseas, with WhatsApp being the key platform for the sharing of digital gifts.

\section{Keeping While Giving}

As noted in Chapter 3 , one of the more interesting digital gifts that appeared across the three sites was the increasing acknowledgement of the sharing of information as a gift. A key example is Satomi, a 31-year-old full-time housewife who lived in a town an hour and a half from the center of Tokyo by train. She lived in a duplex house with her daughter, her husband — who ran a company_-and his parents.

Satomi used LINE on a daily basis with her husband, his parents, and his sister, who were all registered as a group named "family." She frequently received messages from her husband, his mother, and his sister with messages such as "I've finished work now," "I got hung up now because of airplane's delay," or "Why don't you all have dinner at our place?" However, Satomi said, "I communicate with them only in a businesslike manner because I 

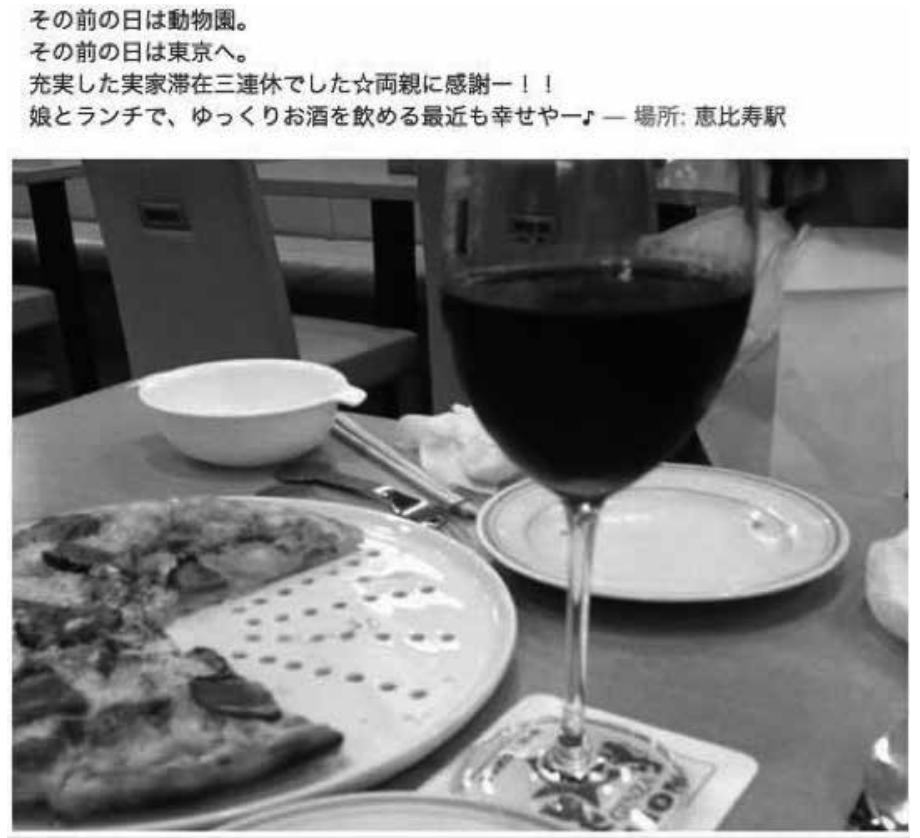

Figure 4.5: Satomi and co-presence as gift

never want them (husband's family side) to know what I did." She sometimes uploaded pictures to Facebook with location information, but not in real time.

In Figure 4.5 Satomi summarized her three-day holiday, together with a photo. She intentionally (or tactically) condensed information about her past three days into a single item in order to share vaguely with "friends" on Facebook. While Satomi wished to diarize her day-to-day activities on Facebook, she also attempted to keep a "proper" distance between her friends and family members by delaying her uploads or by blurring information. Thus, Satomi used social media to help construct distances and proximities, using it to keep her parents informed while also creating a "proper" distance. As highlighted in the extensive literature on gifting (see Weiner 1992), here we see that digital gifting can be used to keep distances as well as create intimacies.

\section{Conclusion: Gifts of Presence/Presents}

In this chapter we have focused upon the ways in which mobile, social and locative media have become part of the gift giving cultures in families across Melbourne, Shanghai and Tokyo. Building upon the extensive literature 
on gifting and the importance of gifting for maintaining social cohesion, we have highlighted the mundane practices of gifting that are occurring through digital means, and how these may be extending previous practices of sharing in families and cultures broadly. In the first section on care and reproduction, we looked at the ways in which WeChat and other platforms are being used to micro-coordinate family life, ranging from the planning of dinner to regulating the emotional state of partners.

The second section focused upon the use of digital gifts such as photos and other information to create a sense of intimacy and co-presence, particularly for families managing distance. In the third and final section we explored how one woman in Japan, Satomi, enacts a classic principle in gifting - the act of keeping while giving. While disclosing information and sharing images of travel and other activities, we saw how Satomi also attempted to maintain distance and keep control over the information that she shared.

As we demonstrated throughout the chapter, locative information conveys more precise information of the whereabouts of family members. It makes it easier for daily communication, which brings convenience for daily life micro-coordination within families. It also creates a sense of co-presence. Meanwhile, differentiated exposure of locative information on digital media indicates a sense of intimacy between certain members. Under such circumstances, sharing location becomes part of the gift economy within families.

\section{References}

Berg, Sara, Alex S. Taylor, and Richard Harper. 2005. "Gift of the gab." Inside Text: Social, Cultural and Design Perspectives on SMS, edited by Richard Harper, Leysia Palen, Alex S. Taylor, 271-285. The Netherlands: Springer-Verlag.

Bergquist, Magnus, and Jan Ljungberg. 2001. "The power of gifts." Information Systems Journal 11: 305-320. Accessed 10/20/2017. DOI: 10.1046/j.1365-2575.2001.00111.x.

Frow, John. 1996. "Information as gift and commodity." New Left Review 219: 89-108. _.1997. Tie and commodity culture: Essays on cultural theory and postmodernity. Oxford: Clarendon Press.

Hjorth, Larissa. 2005. "Odours of Mobility: Mobile Phones and Japanese Cute Culture in the Asia Pacific.” Journal of Intercultural Studies 26 (1- 2): 39-55. DOI: $0.1080 / 075^{256860500074003 . ~}$

Hjorth, Larissa, and Michael Arnold. 2013.Online@Asia-Pacific. London: Routledge. Ito, Mizuko, Misa Matsuda, and Daisuke Okabe (eds.). 2005. Personal, portable, pedestrian: Mobile phones in Japanese Life. Cambridge: The MIT Press. 
Jacobs, Bruce. 1979. "A preliminary model of particularistic ties in Chinese political

alliances: Kan-ch'ing and Kuan-his in a Rural Taiwanese Township." China Quarterly 78: 237-273. DOI: 10.1017/So305741000040467.

Jarrett, Kylie. 2015. Feminism, Labour and Digital Media: The Digital Housewife. London: Routledge.

Kohn, Tamara. 2013. "Stuffed turkey and pumpkin pie: In, through and out of American contexts." Cultural Studies 19 (1):50-72. DOI: 10.5130/csr.v19i1.3075. Ling, Richard and Birgitte Yttri. 2001. "Hyper-coordination." In Perpetual contact: Mobile communication, private talk, public performance, edited by James Katz. 139-169. Cambridge: Cambridge University Press.

Malinowski, Bronislaw. 2014. Argonauts of the Western Pacific. Translated by Adam Kuper. Revised edition. London; New York: Routledge.

Mauss, Marcel. 2002. Essai sur le don. First edition. Abingdon: Psychology Press. -2016. The gift. Translated by Jane I. Guyer. Chicago: HAU.

Miller, Daniel, Ed. 1995. Unwrapping Christmas. Oxford: Oxford University Press. Raheja, Gloria G. 1988. The Poison in the Gift. Chicago: Chicago University Press. Taylor, Alex S., and Richard Harper. 2002. "Age-old practices in the 'New World': A study of gift-giving between teenage mobile phone users." Proceedings of the SIGCHI Conference on Human Factors in Computing Systems. 439-446. New York: ACM. DOI: 10.1145/503376.503455.

Tencent. 2016. “2016 Annual Report.” http://www.tencent.com/zh-cn/content/ir/ rp/2016/attachments/201601.pdf. (In Chinese). Accessed 3 February 2019.

Walder, Andrew. 1986. Communist neo-traditionalism: Work and authority in Chinese industry. Berkeley: University of California Press.

Weiner, Annette B. 1992. Inalienable possessions: The paradox of keeping-while giving. Berkeley: University of California Press.

Yang, Mayfair Mei-hui. 1989. "The gift economy and state power in China." Comparative Studies in Society and History 31 (1): 25-54. DOI: 10.1017/So010417500015656.

-1994. Gifts, favors, and banquets: The art of social relationships in China. New York: Cornell University Press.

Yoon, Song, O., Kwanho Suk, Seon M. Lee, and Eun Y. Park. 2011. “To seek variety or uniformity: the role of culture in consumers' choice in a group setting." Marketing Letters 22: 49-64. DOI: 10.1007/s11002-010-9102-5. 